\title{
Current treatment options for management of anal intraepithelial neoplasia
}

This article was published in the following Dove Press journal:

OncoTargets and Therapy

8 June 2013

Number of times this article has been viewed

\author{
Stephen E Weis ${ }^{1,2}$ \\ 'Division of Dermatology, Department \\ of Internal Medicine, University of \\ North Texas Health Science Center \\ at Fort Worth, ${ }^{2}$ Preventive Medicine \\ Clinic, Tarrant County Public Health, \\ Fort Worth, TX, USA
}

\begin{abstract}
Anal squamous cell cancer is an uncommon malignancy caused by infection with oncogenic strains of Human papilloma virus. Anal cancer is much more common in immunocompromised persons, including those infected with Human immunodeficiency virus. High-grade anal intraepithelial neoplasia (HGAIN), the precursor of anal cancer, is identified by clinicians providing care for patients with anorectal disease, and is increasingly being identified during screening of immunosuppressed patients for anal dysplasia. The traditional treatment for HGAIN has been excision of macroscopic disease with margins. This approach is effective for patients with small unifocal HGAIN lesions. Patients with extensive multifocal HGAIN frequently have recurrence of HGAIN after excision, and may have postoperative complications of anal stenosis or fecal incontinence. This led to the suggestion by some that treatment for HGAIN should be delayed until patients developed anal cancer. Alternative approaches in identification and treatment have been developed to treat patients with multifocal or extensive HGAIN lesions. High-resolution anoscopy combines magnification with anoscopy and is being used to identify HGAIN and determine treatment margins. HGAIN can then be ablated with a number of modalities, including infrared coagulation, $\mathrm{CO}_{2}$ laser, and electrocautery. These methods for HGAIN ablation can be performed with local anesthesia on outpatients and are relatively well tolerated. High-resolution anoscopy-directed HGAIN ablation is evolving into a standard approach for initial treatment and then subsequent monitoring of a disease which should be expected to be recurrent. Another treatment approach for HGAIN is topical treatment, principally with 5-fluorouracil or imiquimod. Topical therapies have the advantage of being nonsurgical and are well suited for treating widespread multifocal disease. Topical treatments have the disadvantage of requiring extended treatment courses and causing a symptomatic inflammatory response. Successful treatment requires adherence to a regime that is uncomfortable at best and at worst painful. Topical treatments can be successful in motivated adherent patients willing to accept these side effects.
\end{abstract}

Keywords: human papilloma virus, anal dysplasia, anal cancer, high-resolution anoscopy, infrared coagulation, perianal dermatosis

\section{Introduction}

Human papillomavirus (HPV) is a common viral infection. Studies, mostly of females with cervical infection, have shown that HPV infections are common and usually transient, and that most anogenital HPV infections resolve spontaneously in immunocompetent patients. ${ }^{1,2} \mathrm{HPV}$ is even more prevalent in immunosuppressed patients than in immunocompetent patients. ${ }^{3-8} \mathrm{HPV}$ infections are less likely to resolve, cause a variety of illnesses that progress more rapidly, and are more severe in Human immunodeficiency virus (HIV)-infected than in non-HIV-infected individuals. Persons
Correspondence: Stephen E Weis

Patient Care Center,

Department of Medicine, 855 Montgomery, Fort Worth, TX76107, USA

Email weistephen@mac.com 
who are coinfected with HIV and HPV also have higher levels of HPV, are often concurrently infected with multiple HPV types, and are more likely to have persistence of HPV infection. ${ }^{4,9-14}$

Infection with specific oncogenic subtypes of HPV, particularly HPV 16 and 18, has been associated with development of anogenital neoplasia. ${ }^{15,16} \mathrm{HPV}$ infection causes a precursor to cervical cancer, ie, cervical intraepithelial neoplasia. ${ }^{17,18}$ There is a similar causal association between HPV infection, which results in development of anal intraepithelial neoplasia (AIN), a precursor of anal squamous cell cancer. ${ }^{19-23}$ The incidence of anal cancer is increasing among men, particularly in HIV-infected men who have sex with men (MSM). ${ }^{21-24}$ While the frequency of progression of high-grade AIN to anal squamous cell cancer is uncertain, there are data suggesting that the long-term risk is in the range of $8.5 \%-13 \% .^{23,25,26} \mathrm{~A}$ recent meta-analysis estimating the risk of anal cancer in HIV-infected MSM confirmed that the risk was substantial, and calculated an anal squamous cell cancer incidence in the highly active antiretroviral therapy era of 78 per 100,000 men. $^{27}$

Clinicians who provide care for patients with anorectal disease commonly encounter AIN in a number of clinical situations. Patients may present with symptomatic perianal or anal disease that on investigation is found to result from AIN. Some patients present with asymptomatic visible disease that is identified on physical examination. Others have AIN discovered after histopathological evaluation of tissue collected during surgical procedures for other anal diseases, eg, hemorrhoidectomy. However, increasingly, immunosuppressed persons who are at high risk for having persistent HPV infection and developing anal cancer are identified as having AIN after screening in primary care. ${ }^{28}$ In the last decade, there have been developments in the medical and surgical options available for patients with AIN. These treatment options are continuing to evolve. For this review, studies concerning treatment of AIN published from 1992 to 2012 were sought using a combination of computerized and hand searches. In situations where results have been published sequentially from the same institution, the publication with the longest follow-up was used. This paper will review the currently available treatment strategies for AIN.

\section{General principles of treatment}

Clinicians treating AIN should be aware of the knowns and unknowns when they plan management of AIN with their patients. First, the primary goal when treating AIN is to prevent anal squamous cell cancer. It is well established that the prognosis of anal cancer is strongly associated with stage of the disease at diagnosis. ${ }^{29,30}$ Anal squamous cell cancer is often diagnosed at a late stage, and approximately $25 \%$ of newly diagnosed anal canal carcinomas are larger than $5 \mathrm{~cm}$ in diameter and clinically node-positive. ${ }^{31}$ While it is accepted that high-grade intraepithelial neoplasia (HGAIN) is the anal squamous cell cancer precursor, the estimates of anal cancer risk are based on relatively small patient populations. ${ }^{23,25,26}$ Therefore, with the risk of anal cancer being uncertain, some patients may choose the least aggressive treatment for AIN, which is periodic digital anal examination. This "watchful waiting treatment" enables detection and treatment of anal cancer at an earlier stage and is associated with an improved outcome. $^{29,30}$

How best to treat HGAIN (AIN-2 or AIN-3) is controversial and cannot be answered directly with data at this time. ${ }^{25,32-34}$ There are no randomized trials directly comparing different treatments. ${ }^{32}$ Studies of AIN treatment are for the most part from single geographic locations, with patient populations that vary in degree of AIN and the proportion of the cohort that is immunosuppressed. Finally, the treatments reported for HGAIN, both medical and surgical, are not standardized. Reports of treatment outcome are mainly in the form of case series and open-label studies, with only a few randomized trials. Some treatments have been described only in case reports. With those caveats, there is general agreement that treatment of AIN depends on the size, number, location, and grade of lesions. ${ }^{34}$ Other factors for clinicians to consider before recommending therapy are the duration of treatment, the expected treatment-related discomfort, the likelihood that the patient will adhere to treatment, and patient preference. Finally, available resources influence treatment as well as the experience of the clinicians treating the patient.

Despite the absence of complete data, clinicians and patients need to make informed treatment decisions. Patients can be confidently informed that condyloma acuminatum and low-grade intraepithelial neoplasia (LGAIN, AIN-1) have very low potential for malignancy. ${ }^{34}$ Some, but not most, clinicians routinely treat LGAIN lesions, recognizing that LGAIN, especially in immunosuppressed populations, can progress to HGAIN. The rationale for treatment of LGAIN includes reducing the risk of progression to higher-grade AIN and to reduce patient anxiety. In our practice, we do not have the clinical capacity to treat patients with asymptomatic LGAIN routinely. Because LGAIN has low potential for malignancy, we recommend that patients with LGAIN attend for annual evaluation, including digital anal examination, anal cytology, and high-resolution anoscopy (HRA) for early 
detection of progression of HGAIN. We do treat patients with symptomatic LGAIN or LGAIN accompanying condyloma acuminata. We explain to patients that we treat their LGAIN lesions to reduce their symptoms and not to reduce the risk of cancer. We presently recommend some form of treatment to almost all patients who have HGAIN (AIN-2, AIN-3). We also recommend that patients with HGAIN who chose not to have treatment have periodic HRA evaluation for the purpose of early detection of progression to anal squamous cell cancer.

Finally, the goals of treating patients with HGAIN are preventing morbidity and mortality from anal cancer without causing disturbances of anal function, ie, continence of stools and flatus. These goals imply that patients with HGAIN would need to have at least several years of expected lifespan to benefit from HGAIN treatment. Therefore, we do not recommend treatment for patients with HGAIN and comorbid illnesses that predict a short-term survival.

\section{Surgical excision for HGAIN}

A survey in 2000 of 663 members of the American Society of Colon and Rectal Surgeons found that $87 \%$ of respondents chose surgical excision with margins as the treatment of choice for AIN-3. ${ }^{36}$ However, the surgical treatment of HGAIN has subsequently become controversial because of reports of incomplete efficacy, frequent recurrence, and complications associated with excisional treatments. ${ }^{23,25,26,33,35-38}$ These reports started to appear in the 1990s when medical immunosuppression for patients with immunologically-based disease and organ transplants became more common, as well as increasing numbers of persons with immunosuppression resulting from HIV. The survey findings reflected surgical opinion at a time when the epidemiology of HGAIN was changing. Back then, HGAIN was most commonly identified in non-immunosuppressed patients, compared with the current situation where HGAIN is commonly identified in immunosuppressed patients.

The outcome of surgical treatment for HGAIN has been consistent from a number of institutions in several countries, and has resulted in a re-examination of treatment options and the development of alternative treatments (see Tables 1 and 2). ${ }^{23,25,26,33,35-38}$ Understanding of these evolving data provided an important background for informed treatment planning in patients with HGAIN. Brown et al reported 34 patients with HGAIN who were treated surgically and followed for a median of 41 months from a single hospital in the UK. ${ }^{33}$ Four of the patients were medically immunosuppressed. Patients with lesions smaller than $1 \mathrm{~cm}$ (15 of 34$)$ treated with simple excision had no disturbance of anal function. HGAIN extended to the margins in 19 of 34 specimens. The margin of excision for AIN was difficult to determine for small and larger lesions, and the excision was frequently not curative. Macroscopic recurrences occurred in 14 of 34 patients, and 12 of these recurrences were at the resection margin and four of 14 patients required more than one excision for macroscopic disease. Five of 19 patients with more extensive disease had postoperative disturbance of anal function. Two had fecal incontinence requiring use of pads and two had fecal incontinence and anal stenosis of a severity requiring permanent colostomy. The authors commented that three patients whose initial histology showed HGAIN were found to have clinically unsuspected invasive anal cancer in the excised specimen. None of the patients with excisions progressed to invasive anal squamous carcinoma. ${ }^{33}$ This patient cohort included patients with extensive disease that were treated aggressively with excisions. While no patient developed cancer, approximately $25 \%$ of patients with extensive disease had anal function defects postoperatively. ${ }^{33}$

Scholefield et al reported on their experience caring for a patient population that included 35 patients with perineal or perianal AIN-3 who were followed for a median of 63 months. ${ }^{26}$ As a result of "significant associated morbidity" from their earlier more aggressive surgical approaches to AIN-3, the authors, whose surgical practice was located at a university hospital in the UK, changed their approach to a more conservative surgical approach for AIN-3. ${ }^{26,37}$ Only patients who had AIN-3 limited to less than $30 \%$ of anal circumference were offered excision. None of the patients in their cohort was known to be HIV-infected, but six of 35 were being treated in the long term with immunosuppressants. ${ }^{37}$ In 12 of 28 patients with localized disease treated by excision, at least one margin was not clear. Macroscopic recurrence of AIN-3 occurred in four patients. All six patients with known immunosuppression had multifocal AIN-3. Three of these six patients developed invasive anal squamous cell carcinoma during follow-up. None of the 28 patients with focal disease treated with excision developed anal squamous cell carcinoma or were reported to have postoperative disturbances of anal function. ${ }^{37}$ The three patients who developed anal squamous cell carcinoma all had multifocal AIN-3 and were not offered excision. These data indicate that limiting surgery to patients with less extensive disease reduces disturbances in anal function that seriously affect quality of life. ${ }^{26,37}$ The data also imply that not treating immunosuppressed patients with extensive disease puts them at high risk for progression to anal squamous cell carcinoma. 
Table I Cohort characteristics of HGAIN treatment trials*

\begin{tabular}{|c|c|c|c|c|c|}
\hline Study ID & Description & $\begin{array}{l}\text { Study } \\
\text { population }\end{array}$ & $\begin{array}{l}\text { Baseline } \\
\text { histology }\end{array}$ & $\begin{array}{l}\text { Age range } \\
\text { (years) }\end{array}$ & Location \\
\hline \multicolumn{6}{|l|}{ Surgery } \\
\hline \multicolumn{6}{|l|}{ Excision } \\
\hline Watson et $\mathrm{a}^{23}$ & Prospective cohort & $\begin{array}{l}52 \text { women, } 20 \text { men; } \\
10 \text { immunocompromised }\end{array}$ & HGAIN $76 \%$ & $49(|8-8|)$ & $\begin{array}{l}\text { Referral hospital, } \\
\text { New Zealand }\end{array}$ \\
\hline Scholefield et a ${ }^{26}$ & Prospective cohort & $\begin{array}{l}26 \text { women, } 9 \text { men; } \\
6 \text { immunocompromised }\end{array}$ & All HGAIN & $43(31-62)$ & University, UK \\
\hline Devaraj and Cosman ${ }^{25}$ & $\begin{array}{l}\text { Retrospective review } \\
\text { of medical records }\end{array}$ & 40 HIV-positive MSM & HGAIN 70\% & $32(24-57)$ & $\begin{array}{l}\text { University and } \\
\text { Veterans } \\
\text { Administration, US }\end{array}$ \\
\hline Brown et $\mathrm{al}^{33}$ & Prospective cohort & 34 men, women & All HGAIN & $39(24-57)$ & UK \\
\hline Marchesa et $\mathrm{al}^{38}$ & $\begin{array}{l}\text { Retrospective review } \\
\text { of medical records }\end{array}$ & 16 men, 31 women & All HGAIN & $46(46-90)$ & $\begin{array}{l}\text { Referral hospital, } \\
\text { US }\end{array}$ \\
\hline \multicolumn{6}{|l|}{ HRA-targeted IRC } \\
\hline Goldstone et $\mathrm{a}^{46}$ & Retrospective & $\begin{array}{l}52 \text { HIV-negative MSM } \\
44 \text { HIV-positive MSM }\end{array}$ & All HGAIN & $36(23-72)$ & $\begin{array}{l}\text { Anorectal surgical } \\
\text { clinic, US }\end{array}$ \\
\hline Weis et a ${ }^{47}$ & $\begin{array}{l}\text { Prospective cohort } \\
\text { (treated versus } \\
\text { untreated) }\end{array}$ & $\begin{array}{l}99 \text { men, } 25 \text { women } \\
\text { All HIV-positive }\end{array}$ & All HGAIN & $40(27-50)$ & $\begin{array}{l}\text { Ryan white } \\
\text { primary care HIV } \\
\text { clinic, US }\end{array}$ \\
\hline Stier et al ${ }^{44}$ & Prospective & $\begin{array}{l}16 \text { men, } 2 \text { women } \\
\text { All HIV-positive }\end{array}$ & All HGAIN & $44(32-53)$ & $\begin{array}{l}\text { Research group, } \\
\text { US }\end{array}$ \\
\hline Cranston et $\mathrm{al}^{45}$ & Retrospective & 68 HIV-positive MSM & All HGAIN & $45(28-65)$ & University, US \\
\hline \multicolumn{6}{|l|}{ HRA-targeted cautery blade } \\
\hline Marks and Goldstone ${ }^{49}$ & Retrospective & $\begin{array}{l}\text { I } 32 \text { HIV-positive MSM } \\
\text { 100 HIV-negative MSM }\end{array}$ & All HGAIN & $42(21-74)$ & $\begin{array}{l}\text { Anorectal surgical } \\
\text { clinic, US }\end{array}$ \\
\hline \multicolumn{6}{|c|}{ HRA-targeted needle cautery } \\
\hline Pineda et $\mathrm{al}^{43}$ & Retrospective & $\begin{array}{l}246 \text { men and women } \\
79 \% \text { immunocompromised }\end{array}$ & All HGAIN & $44(24-7 I)$ & University, US \\
\hline \multicolumn{6}{|l|}{ HRA-targeted $\mathrm{CO}_{2}$ laser } \\
\hline Nathan ${ }^{51}$ & Prospective cohort & $\begin{array}{l}\text { I8I predominantly MSM; } \\
46 \% \text { HIV-positive }\end{array}$ & $\begin{array}{l}49 \% \text { HGAIN } \\
51 \% \text { LGAIN }\end{array}$ & $35(19-62)$ & $\begin{array}{l}\text { Referral hospital, } \\
\text { UK }\end{array}$ \\
\hline \multicolumn{5}{|l|}{ 5-FU } & \\
\hline Snyder et $\mathrm{a}^{58}$ & Retrospective & II HIV-positive MSM & HGAIN 82\% & $45(32-67)$ & University, US \\
\hline Richel et al ${ }^{59}$ & Prospective & 46 HIV positive MSM & HGAIN 74\% & $46(32-72)$ & University, Europe \\
\hline Graham et $a^{57}$ & Prospective & $\begin{array}{l}5 \text { men, } 3 \text { women } \\
\text { I HIV positive }\end{array}$ & All HGAIN & $48(32-75)$ & $\begin{array}{l}\text { Private practice, } \\
\text { US }\end{array}$ \\
\hline \multicolumn{6}{|l|}{ Imiquimod } \\
\hline Wieland et $\mathrm{a}^{63}$ & Prospective & 28 HIV-positive, MSM & HGAIN 73\% & $43(31-69)$ & $\begin{array}{l}\text { University, } \\
\text { Germany }\end{array}$ \\
\hline Kreuter et $\mathrm{a}^{62}$ & Case series & 10 HIV positive, MSM & Not reported & Not reported & $\begin{array}{l}\text { University, } \\
\text { Germany }\end{array}$ \\
\hline Fox et $\mathrm{al}^{64}$ & $\begin{array}{l}\text { Double-blind, } \\
\text { placebo-controlled } \\
\text { trial }\end{array}$ & 64 HIV-positive MSM & All HGAIN & $42(34-50)$ & $\begin{array}{l}\text { Referral Hospital, } \\
\text { UK }\end{array}$ \\
\hline \multicolumn{6}{|c|}{ 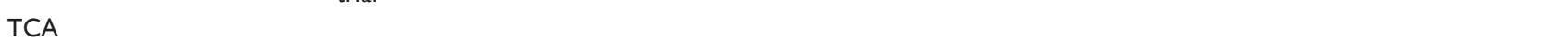 } \\
\hline Singh et $\mathrm{a}^{66}$ & Retrospective & 54 MSM, 35 HIV-positive & HGAIN 52\% & $43(24-71)$ & University, US \\
\hline
\end{tabular}

Notes: *While clinical examinations and histological measurements were used to evaluate patient response to treatments, their definitions significantly varied between studies. Moreover, timing of the measurements was not consistent either within and between studies. In addition, for some studies, the unit of analysis was the lesions targeted while other studies used the individual patient.

Abbreviations: F/U, follow-up; IRC, infrared coagulation; HGAIN, high-grade anal intraepithelial neoplasia; HIV, Human immunodeficiency virus; HRA, high-resolution anoscopy; MSM, men who have sex with other men; TCA, trichloroacetic acid; 5-FU, 5-fluorouracil.

The most recent study on excision of AIN is consistent with prior reports of excision treatment of HGAIN. Watson et al from New Zealand reported the outcome of 72 patients with AIN who were observed for a median follow-up of 60 months. ${ }^{23}$ Approximately $30 \%$ of the patients were immunosuppressed, with 17 receiving immunosuppressants and five being HIV-positive. Postoperative disturbances of anal function were common, and nine patients developed fecal incontinence; of these, four required colostomy. Despite this aggressive treatment, eight of 72 patients (11\%) progressed 
Table 2 HGAIN, outcomes by treatment type

\begin{tabular}{|c|c|c|c|c|}
\hline Study ID & $\begin{array}{l}\text { Anal function } \\
\text { compromised }\end{array}$ & $\begin{array}{l}\text { HGAIN at last } \\
\text { follow-up }\end{array}$ & $\begin{array}{l}\text { Duration } \\
\text { of follow-up }\end{array}$ & Developed ASCC \\
\hline \multicolumn{5}{|l|}{ Surgery } \\
\hline \multicolumn{5}{|l|}{ Excision } \\
\hline Watson et $\mathrm{a}^{23}$ & $9 / 72(13 \%)$ & Not reported & 60 months & $8 / 72(11 \%)$ \\
\hline Scholefield et a ${ }^{26}$ & $0 / 28(0 \%)$ & Not reported & 63 months & $3 / 35(9 \%)$ \\
\hline Devaraj and Cosman ${ }^{25}$ & $1 / 40(3 \%)$ & Not reported & 32 months & $3 / 40(8 \%)$ \\
\hline Brown et al ${ }^{33}$ & $5 / 34(15 \%)$ & Not reported & 41 months & $0 / 34(0 \%)$ \\
\hline Marchesa et a ${ }^{38, *}$ & None reported & See comment* & 104 months & $3 / 47(6 \%)$ \\
\hline \multicolumn{5}{|l|}{ HRA-targeted IRC } \\
\hline \multirow[t]{2}{*}{ Goldstone et $\mathrm{al}^{46}$} & None reported & HIV-positive $18 \%$ & HIV-positive 60 months & $0 / 96(0 \%)$ \\
\hline & & HIV-negative $10 \%$ & HIV-negative 48 months & \\
\hline \multirow[t]{2}{*}{ Weis et $\mathrm{a}^{47}$} & None reported & Treated I3\% & Untreated 1.8 years & Treated $0 / 102(0 \%)$ \\
\hline & & Untreated $93 \%$ & Treated I.3 years & Untreated 2/42 (5\%) \\
\hline Stier et al ${ }^{44}$ & None reported & $38 \%$ & 12 months & $0 / 18(0 \%)$ \\
\hline Cranston et $\mathrm{al}^{45}$ & None reported & $36 \%$ & 4.7 months & $0 / 68(0 \%)$ \\
\hline \multicolumn{5}{|l|}{ HRA-targeted ECA } \\
\hline \multirow[t]{2}{*}{ Marks and Goldstone $e^{49}$} & None reported & HIV-negative $17 \%$ & HIV-negative 21 months & $1 / 232(0.4 \%)$ \\
\hline & & HIV-positive 3I\% & HIV-positive 20 months & \\
\hline \multicolumn{5}{|l|}{ HRA-targeted needle cautery } \\
\hline \multicolumn{5}{|c|}{ F/U IRC or TCA } \\
\hline Pineda et $\mathrm{al}^{43}$ & $2 / 246(0.8 \%)$ & $22 \%$ & 41 months & $3 / 246(1.2 \%)$ \\
\hline \multicolumn{5}{|l|}{ HRA-targeted $\mathrm{CO}_{2}$ laser } \\
\hline Nathan et $\mathrm{a}^{51, * *}$ & None reported & $37 \%$ at 12 months & 19.1 months & $0 / 18 \mid(0 \%)$ \\
\hline \multicolumn{5}{|l|}{ Topical medical therapy } \\
\hline \multicolumn{5}{|l|}{ 5-FU } \\
\hline Snyder et $\mathrm{al}^{58}$ & None reported & $72 \%$ & Not reported & $0 / I I(0 \%)$ \\
\hline Richel et al ${ }^{59}$ & None reported & $30 \%$ & Not reported & $0 / 46(0 \%)$ \\
\hline Graham et a ${ }^{57}$ & None reported & $13 \%$ & 39 months & $1 / 8(13 \%)$ \\
\hline \multicolumn{5}{|l|}{ Imiquimod } \\
\hline Wieland et $\mathrm{a}^{63}$ & None reported & $2 / 22(9 \%)^{* * *}$ & 9.5 months & $0 / 28(0 \%)$ \\
\hline Kreuter et $\mathrm{a}^{62}$ & None reported & AIN reduced in all & Not reported & $0 / 10(0 \%)$ \\
\hline Fox et $\mathrm{al}^{64, * * * * *}$ & None reported & $39 \%$ & 36 months & $2 / 64(3 \%)$ \\
\hline \multicolumn{5}{|l|}{ TCA } \\
\hline Singh et $\mathrm{al}^{66}$ & None reported & $39 \%$ & Not reported & $0 / 54(0 \%)$ \\
\hline
\end{tabular}

Notes: *Twenty-six patients were treated with wide local excision, 15 by local excision, 5 by $\mathrm{CO}_{2}$ laser, and one by abdominoperineal resection; for these, recurrence rates were $6 / 26(23 \%), 8 / 15(53 \%), 4 / 5(80 \%)$, and $0 / I(0 \%)$, respectively; ** 14 I had laser ablation, and $60 \%$ of these had additional excision or imiquimod; ***efficacy reported for 22 adherent subjects; *****placebo group and nonresponders offered open-label imiquimod.

Abbreviations: AIN, anal intraepithelial neoplasia; ASCC, anal squamous cell carcinoma; ECA, electrocautery ablation; F/U, follow-up; 5-FU, topical 5-fluorouracil; HIV, Human immunodeficiency virus; HRA, high-resolution anoscopy; HGAIN, high-grade anal intraepithelial neoplasia; IRC, infrared coagulation; TCA, trichloroacetic acid.

to invasive anal squamous cell carcinoma. ${ }^{23}$ These studies, when taken together, have changed the view of excision therapy for HGAIN. It is now considered by many not to be an ideal treatment for patients with extensive or multifocal HGAIN. The findings leading to this change include incomplete excisions that leave clinically inapparent HGAIN at surgical margins that subsequently recur, frequent HGAIN recurrences even in patients whose surgical sites indicate that the HGAIN has been completely excised, and patients who have excisions for more than minimal disease often have clinically important post-procedure morbidity. ${ }^{23,26,33,37}$

As a result of these data, some colorectal surgeons have suggested that treatment of HGAIN, especially in immunocompromised persons, is futile because recurrences are frequent, and progression to anal cancer occurs despite excision. ${ }^{25,26,37}$ It was further suggested that, because chemoradiation for small invasive anal carcinomas is effective and that colostomy can usually be avoided if lesions are identified early, persons with HGAIN should not be treated in an attempt to prevent progression of HGAIN to squamous cell carcinoma, but could instead be monitored regularly for progression and only treated if squamous cell carcinoma develops. ${ }^{25,37} \mathrm{~A}$ report of the outcome of "expectant management of dysplasia" from a practice located at a US University and Veterans Administration practice followed $40 \mathrm{HIV}$-infected patients with AIN for a mean of 32 months. ${ }^{25}$ Patients were recommended to have a clinical examination every 6 months, with biopsies of new macroscopic or symptomatic disease. Of these 40 patients, 28 had AIN-3. During follow-up, three of the patients with AIN-3 developed squamous cell carcinoma 10, 16, and 84 months after their diagnosis of AIN-3. All three cancers were less than $2.5 \mathrm{~cm}$ in diameter. ${ }^{25}$

Comparisons between these studies that used excision for treatment of HGAIN and observation must be interpreted 
cautiously because each study included different populations with varying extents of disease and proportions of immunosuppressed patients. The reports were from different practice settings using different surgical approaches and variable follow-up methodology. Despite these differences, it is clear that the patient population with HGAIN has changed in the last two decades. Depending on practice location and the local prevalence of HIV, in most areas, the majority of patients with HGAIN are now immunosuppressed and more likely to have multifocal disease, where examination limited to visible macroscopic disease underestimates the AIN disease burden.

\section{High-resolution anoscopy}

HRA is a relatively recently described technique for identifying AIN that combines magnification with anoscopy. ${ }^{39}$ HRA offers patients the advantages of initial diagnosis and surveillance of AIN. HRA uses acetowhitening to identify areas of dysplastic tissue for closer evaluation. After shortduration exposure to $3 \%-5 \%$ acetic acid (vinegar), dysplastic epithelium demonstrates relatively greater acetowhitening relative to normal epithelium. This allows the clinician to identify and focus a magnified examination on the acetowhite areas. Magnification is provided by a standard colposcope and allows inspection of the entire circumference of the distal rectum, transformation zone, anal canal, and perianal region. Acetowhite areas when examined with magnification
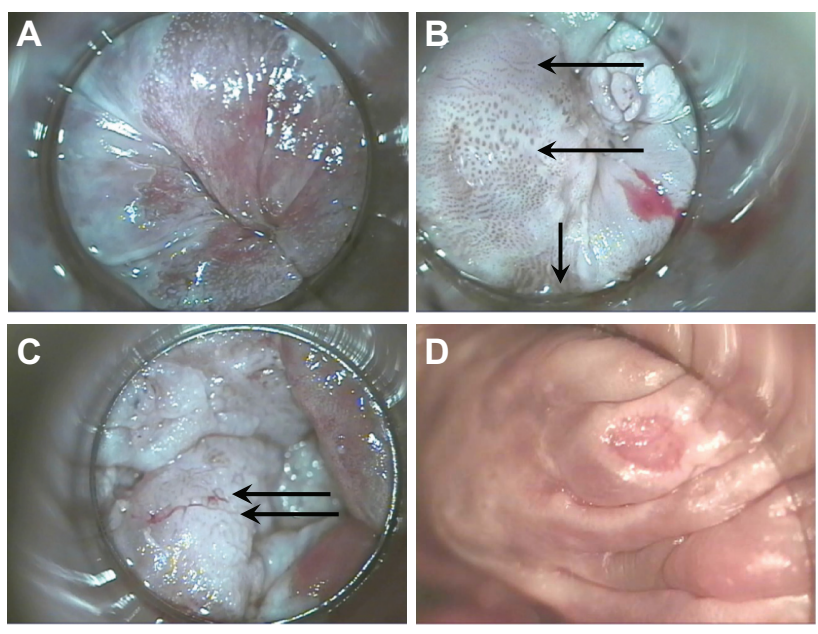

Figure I High-resolution anoscopy appearance of anal epithelium. (A) Normal and (B) vascular patterns of high-grade dysplasia; upper arrow points to fine irregular punctation, middle arrow points to coarse irregular punctation, lower arrow points to prominent and dilated linear vessels. Biopsies of all three areas were AIN-3. (C) Vascular patterns of high-grade dysplasia. Arrows point to mosaic pattern with punctation in the middle of the mosaic tiles. Biopsy showed squamous cell cancer in situ. (D) Surface findings of high-grade dysplasia include ulceration. Biopsy showed AIN-3.

Abbreviation: AIN, anal intraepithelial neoplasia. demonstrate characteristic vascular and surface changes of AIN (Figure 1). These findings are associated with HGAIN, allowing for directed biopsies. ${ }^{39}$ HRA requires no anorectal preparation and is performed as an outpatient procedure. After HRA-directed biopsies, patients can be discharged with no treatment or simple analgesics, and can continue their usual activities and diet. As a result, HRA with biopsy can be used to identify and map the area of the anus with AIN and can be performed periodically as part of surveillance to identify AIN before it becomes macroscopic.

HRA is a relatively simple procedure for the patient and clinician. ${ }^{39}$ The pre-HRA patient visit includes an evaluation for risk of bleeding, medical risks, and patient education. We do not recommend any patient preparation and actively encourage patients not to take enemas or to try and cleanse themselves prior to the procedure. Such preparation can potentially affect cytology and the appearance of the anoderm. We occasionally prescribe benzodiazepines before the procedure for situational anxiety. Perioperative antibiotics are not recommended unless patients meet the recommendations for endocarditis or joint prophylaxis. ${ }^{40,41}$ HRA is most comfortable for the patient when performed in the lateral decubitus position or dorsal recumbent position. Once positioned, anal cytology is collected and 5\% lidocaine is applied liberally to the anal canal during digital anal examination. ${ }^{39}$ An anoscope coated with a mixture of surgical lubricant and 5\% lidocaine cream is then used to introduce an applicator stick wrapped in gauze soaked in 5\% acetic acid into the anal canal. After this has been in place for at least one minute, a colposcope is used to view the walls of the anal canal under magnification. Additional 5\% acetic acid is applied to the areas being examined during the procedure, and the most abnormal acetowhite areas that are suspicious for AIN are biopsied with Baby Tischler Forceps. Homeostasis is achieved with Monsel's solution. ${ }^{39}$

\section{Infrared coagulation of AIN}

Infrared coagulation, which has been used successfully for treatment of internal hemorrhoids and condyloma, has recently been described as an outpatient technique for treating AIN. ${ }^{42}$ Goldstone recognized that the standard surgical techniques had excessive morbidity and were unsuitable for treating multifocal disease, which is increasingly being identified in immunosuppressed patients. He theorized that intraepithelial AIN, which by definition is confined to the epidermis, would be amenable to infrared coagulation ablative therapy. He felt that infrared coagulation ablation, because of its limited depth of destruction and hemostatic effects, could be safely performed on outpatients by nonsurgeons (personal 
communication, Stephen E Goldstone). Subsequent to his initial description, there have been many reports of infrared coagulation ablation of AIN. ${ }^{42-47}$

Infrared coagulation ablation offers important advantages for patients being treated for AIN. Like HRA, infrared coagulation requires no anorectal preparation, and is performed as an outpatient procedure under local anesthesia. Infrared coagulation provides homeostasis simultaneously with tissue coagulation. Also, it does not create the vapor plume created by electrocautery or laser surgery, so does not require use of a smoke evacuator, which is rarely found in nonsurgical offices. The depth of tissue coagulation (in millimeters) is approximately equal to the length of the pulse applied. For example, a 1.5 second pulse penetrates the tissue to a depth of approximately $1.5 \mathrm{~mm}$. This allows for local treatment without damaging deeper tissues. These characteristics have allowed infrared coagulation to be used successfully by nonsurgeons. ${ }^{43-45,47}$ After infrared coagulation, most patients are able to continue their usual activities with simple analgesics and a high fiber diet after 1-2 days of oral narcotics and tub soaks. Infrared coagulation has a much lower frequency of functional adverse outcomes, eg, anal stenosis and fecal incontinence, than does excision. ${ }^{43,46}$ In additional, once healed from the treatment, infrared coagulation does not affect sexual function. As a result, infrared coagulation treatment is ideal for a disease that is often multifocal and recurrent.

The first step in treating AIN with infrared coagulation is localization by HRA. Unlike the cervix, which remains stationary during colposcopy, the anal canal differs in appearance based on how and at what angle the anoscope is held. Therefore, AIN must be reidentified after biopsy confirmation. There are different methods used to aid in identification of AIN for treatment after biopsy. We document lesions suspicious for HGAIN to be biopsied in two ways. They are photographed and the appearance of lesions and biopsy sites on HRA are described in the medical record using a clock-face diagram, with the coccyx representing 12 o'clock. After the biopsy results are available, HRA is repeated and, using photographs, medical records, and biopsy reports, the areas with HGAIN are again identified and infiltrated with $1 \%$ lidocaine combined with 1:100,000 epinephrine for local anesthesia. Lesions are coagulated repeatedly with infrared coagulation in 1.6 second pulses until the entire surface and an approximately $3 \mathrm{~mm}$ surrounding border are coagulated. The coagulated tissue can then be removed with downward pressure combined with a rotary motion on the eschar using a large Scopette or
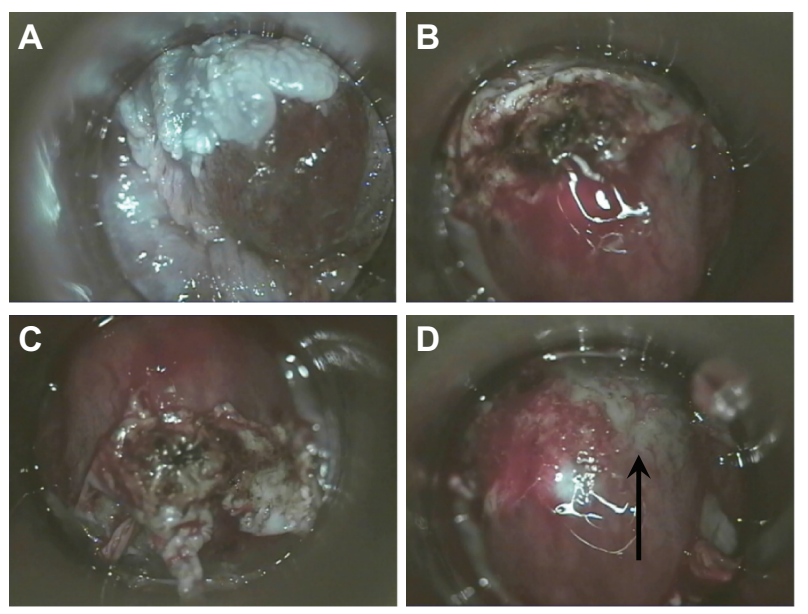

Figure 2 (A) High-resolution anoscopic appearance of previously biopsied AIN2 lesion. (B) Appearance of the lesion after IRC. Lesion has been twisted with a Scopette and the coagulated tissue is buckled up. (C) Eschar is completely loosened by additional pressure with twisting of Scopette. (D) Eschar removed, note coagulated (arrow) and noncoagulated submucosal vessels.

Abbreviations: AIN, anal intraepithelial neoplasia; IRC, infrared coagulation.

small cotton Q-tip (Figure 2). If the tissue remains adherent after repeating this maneuver several times, it can then be removed by curettage with a small Fox Dermal curette or with Baby Tichler forceps. Infrared coagulation is then repeated and the process continued until the submucosal vessels are identified and coagulated (Figure 2). The number of HGAIN lesions that can be treated in a single procedure is dependent on the extent of disease and patient tolerance. All patients are given verbal and written post-procedure instructions. These include advice to consume a high-fiber diet (our instructions recommend consuming one cup of All Bran cereal daily), to avoid anal sexual activity until one week after last bleeding or anal pain, and sitting and soaking in a tub of hot water frequently for the first few days after infrared coagulation to reduce pain. We prescribe hydrocodone plus acetaminophen as needed for pain and before bowel movements to reduce pain for the first few days after the procedure.

Comparisons of studies using infrared coagulation for the treatment of HGAIN must be interpreted cautiously because each study included different populations, was carried out in different practice settings, used slightly different infrared coagulation methods, and had different follow-up methodology. Some studies using infrared coagulation ablation for treatment included only persons with limited disease, others included patients with generalized disease, and no study as yet has correlated the extent of HGAIN disease with response to infrared coagulation. ${ }^{41-46}$ There were variable numbers of immunocompromised patients, and the studies included different proportions of HIV-infected MSM, non-MSM men, and women. ${ }^{42-47}$ The definition of HGAIN 
was also study-specific, with some authors using HGAIN histology as an endpoint and other studies using a histologycytology composite endpoint for HGAIN. ${ }^{42-47}$ Some authors analyzed their study data by "HGAIN lesion" as the unit of observation while others used "patient". HRA-guided identification of lesions was also not standardized, with some programs using 3.5\% acetic acid and others using $5 \%{ }^{42-47}$ In addition, ablative infrared coagulation treatment was not standardized. One group used 1.6 second treatment pulses and treated a margin around the lesion. ${ }^{47}$ Other studies reported using a 1.5 second treatment pulse and did not treat margins. ${ }^{42-47}$ Despite these differences, there was similar efficacy in patients treated with infrared coagulation, that was consistently in the range of $64 \%-87 \%{ }^{42-47}$ Postoperative disturbances of anal function were uncommon, with less than $1 \%$ of patients developing anal stenosis and no patients having fecal incontinence. ${ }^{43,46}$ The only study of infrared coagulation treatment that included a comparison group comprised patients who either delayed treatment or did not have treatment and were compared with treated patients. The authors found significantly more untreated than treated patients who had HGAIN on re-evaluation (93\% versus $13 \%$ ). Two of the untreated patients and none of the treated patients developed squamous cell carcinoma. ${ }^{47}$ These data on infrared coagulation treatment, when viewed together across multiple study sites, different populations, and nonstandardized methods, demonstrate that infrared coagulation ablation is an effective treatment for HGAIN in HIV-infected patients.

\section{HRA-guided electrocautery ablation}

Another alternative ablative technique is HRA-guided electrocautery ablation, which has been reported by two US centers. ${ }^{48,49}$ HRA-guided electrocautery was initially described as an operating room technique for extensive HGAIN disease in 2002. ${ }^{48}$ It has recently been reported again as a potential HGAIN treatment in a larger group with longer follow-up, including 132 HIV-positive MSM followed for a median of 19 months and 100 HIV-negative MSM followed for 17.5 months. ${ }^{49}$ In the most recent study, all patients were treated with electrocautery ablation for HGAIN at the beginning of the observation period. The practice location was a single surgical practice in New York City specializing in the treatment of HPV-related anorectal disease. ${ }^{49}$ Recurrence was defined as HGAIN confirmed by either cytologic or biopsy occurring after treatment. The frequency of recurrence was higher in patients who had multiple HGAIN lesions at presentation, ie, a higher disease burden. At final evaluation of the cohort, $83 \%$ of
HIV-negative patients and $69 \%$ of HIV-positive patients were free of HGAIN. Only one patient $(0.4 \%)$ developed squamous cell carcinoma during the follow-up period. Unlike infrared coagulation, hyfrecator electrocautery ablation creates a smoke plume that must be removed with a smoke evacuator to prevent aerosol transmission of HPV. The author, who has extensive experience in identifying and treating AIN, reported that no patients developed anal stenosis or incontinence. ${ }^{49}$ The author compared his results using HRA-guided electrocautery ablation with infrared coagulation of HRA, and concluded that the outcome of electrocautery ablation was similar and that the choice of modality for ablation should be based on clinician preference. He further concluded that electrocautery ablation is an effective treatment for HGAIN and, like infrared coagulation, can be used safely in the office. ${ }^{49}$

\section{$\mathrm{CO}_{2}$ laser fulguration}

$\mathrm{CO}_{2}$ laser fulguration of anal canal tumors has been used successfully to treat patients at high operative risk. ${ }^{50}$ One study reviewed the experience of a single institution using $\mathrm{CO}_{2}$ laser, alone or in combination with surgical excision and/or imiquimod, to treat HGAIN and LGAIN. ${ }^{51}$ The 141 subjects included primarily MSM. They found that $63 \%$ of patients were disease-free at 12 months. However, because the patients in this report were treated with multiple modalities, it is difficult to determine the independent effect of $\mathrm{CO}_{2}$ laser treatment. ${ }^{51}$

\section{Medical treatment options for HGAIN Topical 5-fluorouracil}

Use of medical treatments for AIN has gained increasing recognition. Topical fluorouracil (5-FU) and imiquimod have both been used successfully for treatment of a wide range of mucosal diseases, including actinic cheilitis, Bowen's disease of the anal and vulvar mucosa, and genital and perianal condyloma. ${ }^{52-56}$ Topical 5-FU has a well established role in the treatment of actinic keratoses and nonmelanoma skin cancers. ${ }^{53}$ Fluorouracil 5\% cream or solution is a treatment approved by the United States Food and Drug Administration (FDA) for actinic keratosis and superficial basal cell carcinoma. 5-FU is an antimetabolite that interferes with the synthesis of DNA and to a lesser extent inhibits the formation of RNA. While there have been a number of trials of topical $5-\mathrm{FU}$ in the prevention of progression of lower genital tract neoplasia to invasive carcinoma in HIV-positive and HIV-negative women, mucosal use of topical 5-FU remains 
off-label. ${ }^{52-56}$ Topical treatment potentially has substantial advantages for treating AIN because it can be applied by the patient and is a superficial treatment with minimal risk of long-term loss of anal function, particularly incontinence of stool and flatus or anal stenosis. Topical therapies are well suited for treating widespread multifocal disease. However, topical treatments have the disadvantage of requiring extended treatment courses and causing an inflammatory response that is at best uncomfortable and can be so painful as to be treatment-limiting.

Treatment of anogenital mucosal disease with 5-FU is not standardized, and the amount and frequency of 5-FU used are variable. There have been several case series specifically reporting the outcome of 5-FU treatment for AIN. In a private practice setting in Kansas, Graham et al prospectively treated 11 patients with histologically proven perianal Bowen's disease using 5-FU 5\% twice daily for 16 weeks. ${ }^{57}$ Only one patient was immunosuppressed and had HIV. In addition, some of the patients had excision of focal macroscopic disease. Most patients had to interrupt 5-FU for 4-7 days and several had repeated interruptions. No patient missed more than 3 weeks of treatment. The patients had a mean follow-up of 39 months. The HIV-infected patient was the only nonresponder and the other 10 remained without evidence of AIN at follow-up..$^{57}$ In a retrospective study of the efficacy of 5-FU done at a university medical center, the patient population included 11 HIV-infected MSM with AIN. ${ }^{58}$ Treatment-related discomfort resulted in one patient stopping therapy and seven reducing the frequency of treatment. Treatment duration was variable, from 7 to 36 weeks. ${ }^{58}$ After treatment, the area of AIN was reduced in $55 \%$ of patients (six of 11 ). Further, the grade of dysplasia was reduced in $27 \%$ of patients (three of 11). ${ }^{58}$

In a prospective trial from two European academic centers, $46 \mathrm{HIV}$-infected MSM were enrolled, ${ }^{59}$ approximately $75 \%$ of whom had multifocal HGAIN. The purpose of this pilot study was to evaluate the safety and efficacy of treatment with $5 \%$ 5-FU for all grades of AIN. The treatment was one gram of 5-FU cream applied intra-anally twice weekly at night with a "standard anal applicator for cream" ${ }^{59}$ Patients were allowed to interrupt treatment for up to a week for severe symptoms or reduce the frequency to once weekly for mild symptoms. Side effects were frequent, and occurred in $85 \%$ of participants; $37 \%$ had mild side effects, and $48 \%$ had moderate to severe side effects. Five of 46 participants had treatment interruptions or reduced frequency of treatment because of side effects. Eighteen participants (39\%) had complete clearance of AIN and eight (17\%) had a partial response. Seventeen participants
(37\%) did not respond. ${ }^{59}$ These data taken together demonstrate the efficacy of 5-FU, but also demonstrate that the optimal dose, frequency of administration, and duration of treatment are uncertain. In our practice, we use topical 5-FU for patients with extensive disease, including those with combined perianal and anal HGAIN. Our clinical impression is that 5-FU works well, but only for patients who are motivated enough to tolerate the side effects for treatment of extensive and often severely symptomatic AIN.

We spend a much greater amount of time in patient education when treating AIN with topical treatments than for other treatments, because we expect every patient to have clinically important treatment-related side effects and because all of the medications are used off-label. We discuss that AIN is not an FDA-approved indication for treatment with 5-FU. We discuss further that there are no FDA-approved medical treatments for AIN, and any proposed topical medical treatment would be off-label. We explain that the rationale for use of 5-FU comes from a variety of sources, including case series, open-label studies, and randomized controlled trials of other skin and mucosal diseases that support using topical 5-FU in the treatment of AIN. We also explain that the different reports using 5-FU for AIN have used different schedules of treatment and different concentrations and forms of 5-FU, and have had different outcomes.

At our clinic, we use an intermittent 6-month 5-FU treatment regimen following a one-month treatment run-in period. Our regime is designed to be intermittent, given that all published 5-FU treatment schedules used in HGAIN have required interruptions because of patient discomfort. Our regime generally allows treatment to occur without interruption. The one-month treatment run-in period is designed to give the patient experience with the discomfort of treatment and for the clinician to be able to assess the patient's pain response and determine the need for analgesics prior to initiating the regime. There are two treatment cycles per month, on days 1-5 and days 15-20. These cycles allow the treatment days to be independent of the number of days in the month. During the first run-in cycle, 5-FU is used at bedtime on the first, third, and fifth day. The second cycle is once nightly for 5 nights. The patients are reassessed after the second run-in cycle to determine the extent of discomfort resulting from their treatment, to reassure them that the pain is not, as is usually interpreted a symptom of a problem, but instead is a sign of therapeutic efficacy of 5-FU. If the patient has severe discomfort, we give analgesics and if necessary treat with oncenightly cycles on the same schedule. If the patient is able to tolerate once nightly 5 -day cycles, we increase the frequency 
of topical 5-FU to twice daily. The goal is 12 five-day cycles of treatment with twice daily 5-FU (Figure 3 ).

Applying medication to the entire anal canal is not simple for patients because it is applied blindly. The patient or their partner is instructed to put on latex gloves, put one quarter of a fingertip unit of 5-FU on the index finger, and rub the medication into the reachable anal canal. A fingertip unit of medication is the amount of ointment expressed from a tube from the distal interphalangeal joint to tip of the finger. Patients are advised to massage this medication into an approximate anal depth of between the first and second crease of their finger, ie, midway between the distal and proximal interphalangeal joints. The procedure is then repeated with the other hand so that the medication can be applied to the full anal canal. If there is perianal involvement, the same process is performed on the skin of the perianus. We carefully explain why using both hands is necessary, because the wrist cannot distribute the medication through 360 degrees. We have had several patients who have had diffuse disease prior to treatment who had an excellent response, but with focal failure of treatment. After questioning these patients on how they applied the medication, failure was attributed to applying the medication using only one hand and missing an area (Figure 4). All patients receive printed instructions that repeat the education given verbally.

Patients are seen at least once a month and re-educated on application technique, and that signs of inflammation, including itching, burning, and pain, are evidence that

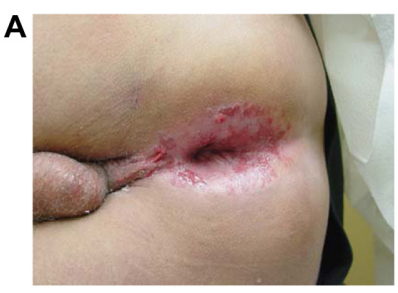

B

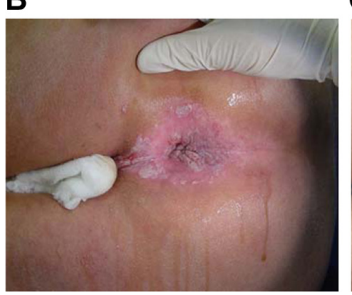

C

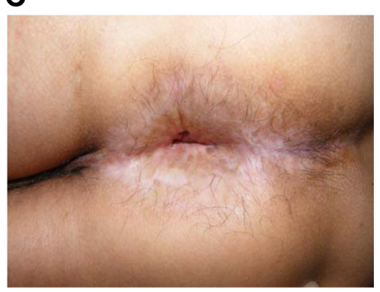

Figure 3 Medical treatment of intraepithelial neoplasia. (A) Appearance of perianal high-grade anal intraepithelial neoplasia. Multiple biopsies all showing either AIN-3 or squamous cell cancer in situ. (B) Perianal appearance after $5 \%$ acetic acid. (C) The patient was treated with topical 5 -fluorouracil. This is the appearance of perianus after 2 years of observation.

Notes: Because of extensive disease, he continues to use prophylaxis in a onemonth cycle every 6 months. He has had no recurrence. He has been observed for 5 years with no clinical or histologic evidence of recurrence.

Abbreviation: AIN, anal intraepithelial neoplasia.

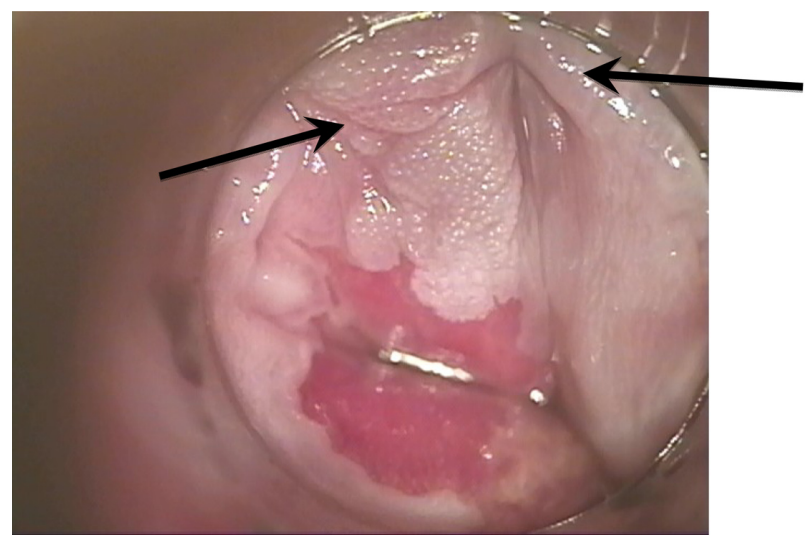

Figure 4 This figure illustrates the effect of incorrectly applying topical 5-fluorouracil. The patient applied 5-fluorouracil with one hand only and left one area of HGAIN incompletely treated. The arrows point to the HGAIN that was incompletely treated. Abbreviation: HGAIN, high-grade intraepithelial neoplasia.

the 5-FU treatment is working as expected, and should be interpreted positively as a sign of response and not negatively as a sign of an adverse reaction. We believe that the run-in period gives the patient the opportunity to experience less intense inflammation and tolerate twice-daily treatment better. It also allows the caregiver at one month follow-up evaluation an opportunity to prescribe analgesics or, if a very intense reaction occurs, to continue treatment with once daily 5-FU rather than increasing the treatment to twice daily. Most patients experience some irritation and pain after several days of treatment, that peaks after treatment day 5 and then resolves or subsides prior to the next treatment cycle. Examination during periods of irritation will reveal multiple superficial erosions. If the discomfort is still too severe when the next cycle is due to resume, then that cycle is skipped and resumed again at the next scheduled time. The missed cycle is added to the end of treatment. This simplifies the treatment regimen and reduces unintended nonadherence.

\section{Topical imiquimod}

Imiquimod is a topically applied agent with antiviral and antitumor activity, and works through an immunomodulator mechanism by increasing the activity of Toll-like receptors. ${ }^{53}$ Imiquimod is approved by the FDA for the treatment of external genital and perianal warts, actinic keratoses, and superficial basal cell carcinoma, and is widely used..$^{53}$ In addition, imiquimod has been used off-label for treatment of a number of diseases. A study of reported off-label imiquimod use in 2009 found case reports, letters, and small trials documenting imiquimod use in over 60 conditions. ${ }^{60}$ There are unique concerns about using imiquimod in the anal canal where, because of its proximity to the rectum, imiquimod could be more readily systemically 
absorbed. Unlike 5-FU that is routinely used intravenously and has systemic toxicity which is well known, the systemic toxicity of higher concentrations of imiquimod that could occur from rectal absorption is unknown.

Imiquimod is the best studied of the off-label medical treatments for AIN, and has been shown in multiple small studies to be an effective treatment for AIN. ${ }^{61-64}$ In a study from Germany, 10 HIV-positive MSM with different grades of AIN were treated with imiquimod $5 \%$ cream three times a week for a maximum of 16 weeks. ${ }^{61}$ All patients showed regression of AIN by at least two grades. HPV 16 was not detectable by polymerase chain reaction in any of the patients at follow-up. ${ }^{61}$ In a prospective study of $28 \mathrm{HIV}$-infected MSM with AIN from Germany who were treated with anal imiquimod suppositories, 17 (77\%) of 22 compliant patients and $17(61 \%)$ of all study patients were free of disease by clinical and histologic criteria after 16 weeks of therapy. ${ }^{63}$ The authors also found the numbers of HPV copies and types were significantly reduced in adherent patients. ${ }^{63}$ The significant reduction in HPV copies persisted during a median follow-up of 7 months. The authors theorized that the persistent reduction in HPV copies might have been due to induction of HPV-specific T cell immunity. ${ }^{63}$ In a prospective, randomized, double-blind study of imiquimod versus placebo from the UK, the placebo group after re-evaluation was given the opportunity to use open-label imiquimod therapy. ${ }^{64}$ The authors found that $61 \%$ (29 of 47) of the patients remained free of HGAIN after a median follow-up of 33 months. ${ }^{64}$ These studies demonstrate that imiquimod was useful for treating patients with widespread multifocal AIN, who are difficult to treat. ${ }^{61-64}$ Imiquimod can be used as primary therapy or as an adjunct to destructive therapy. ${ }^{51}$

Studies of imiquimod treatment for HGAIN share the same limitations, as do reports of other treatments for this condition. Studies have used different definitions of AIN, with some using histology as an endpoint and others using a combined endpoint of cytology plus histology. ${ }^{61-64}$ All have included only MSM, and extrapolating the outcomes of these studies to the broader AIN population which includes women, and non-MSM, non-HIV-infected, and non-immunosuppressed patients is not ideal. ${ }^{62-64}$ Different forms of treatment were used, with some using imiquimod suppositories that are not widely available and others using cream. Different amounts of imiquimod cream were used, with some studies using a half sachet of cream and other studies using a full sachet. ${ }^{61-64}$

We give patients similar detailed instructions about imiquimod treatment of HGAIN as described above for 5-FU treatment. Again, patient education is essential because we expect every patient to have clinically important treatmentrelated side effects to imiquimod, and its use is off-label. We discuss that treatment of AIN using imiquimod is not an FDA-approved use. We further discuss that there are no FDA-approved medical treatments for AIN, and any proposed topical medical treatment would be off-label. The patient or their partner is instructed to put on latex gloves, put one quarter of a sachet of imiquimod on the index finger, and rub the medication into the anal canal at bedtime on Monday, Wednesday, and Friday. The patients are advised to massage this medication into an approximate depth of between the first and second crease of their finger, ie, midway between the distal and proximal interphalangeal joints. The procedure is then repeated with the other hand so that the medication is applied to the entire anal canal. The dose we use per treatment is one half sachet of cream. If there is perianal involvement, the same process is performed on the skin of the perianus. Patients also receive printed instructions in addition to these verbal instructions.

Similar to the pretreatment education process used for patients treated with $5-\mathrm{FU}$, we educate patients that signs of inflammation, including itching, burning, and pain, are evidence that the imiquimod treatment is working, and are expected if treatment is successful. We discuss with them that these symptoms should be interpreted positively as a sign of response and not negatively as a sign of an adverse reaction. Further, we discuss that imiquimod can lead to transient flulike symptoms on the day following treatment. We see patients after 2 weeks of treatment, and if they do not have symptoms or signs (erythema or erosions) of inflammation, we increase the imiquimod frequency to nightly Monday through Friday. We see patients monthly during the 16-week treatment course to treat discomfort and encourage adherence. If inflammatory symptoms cannot be controlled with simple analgesics, we advise the patients to hold the imiquimod until symptoms improve and then resume treatment.

Adherence with treatment is difficult to achieve with uncomfortable treatments. Typical levels of adherence are illustrated by 28 patients who were treated with imiquimod, of whom six (21\%) applied the imiquimod occasionally or not at all. ${ }^{61}$ Not surprisingly, those who did not use imiquimod regularly did not show any clinical response. Nonadherence with treatment recommendations for imiquimod is frequent and is likely related to the duration of treatment and treatment-related discomfort. Adherence is likely better with destructive surgical treatments or excisions than with topical treatments. 


\section{Trichloroacetic acid and bichloroacetic acid}

Topical $85 \%$ trichloroacetic acid (TCA) or bichloroacetic acid are directly cytotoxic therapies that destroy tissue by chemical coagulation of proteins. They are recommended by the US Centers for Disease Control and Prevention as first-line treatments for condyloma acuminatum. ${ }^{65}$ As a result, many clinicians are experienced in using TCA to treat anogenital condyloma acuminatum and TCA is readily available. TCA treatment has other advantages, including being inexpensive, not requiring anesthesia, being without systemic side effects, requiring minimal clinician training, and being safe for use in pregnancy. ${ }^{65,66}$ Treatment with TCA involves first identifying AIN lesions by HRA, and then a small amount of TCA is applied directly and repeatedly to the AIN lesion until it turns a dense white color ${ }^{66}$ The endpoint of treatment is when the entire lesion "frosts" and appears white. The procedure we use is to first pour several $\mathrm{mL}$ of TCA into a small cup. We then tilt the cup and dip the wooden stick end of a cotton swab and let it become saturated with TCA. We then apply the stick saturated with TCA to the AIN lesion, being careful to not get the TCA on adjacent normal tissues. Because TCA has low viscosity, it can spread easily to normal tissues that can also become chemically coagulated. ${ }^{65}$ If this occurs, the TCA can be blotted up with the cotton end of the cotton swab. In addition, the TCA can, if necessary, be neutralized with sodium bicarbonate (ie, baking soda). The TCA should be allowed to dry before the patient sits or stands.

There has been a single report of TCA treatment in 54 patients with AIN. The study included a mixture of immunosuppressed patients, $65 \%$ of whom were HIVinfected. Patients were treated with topical TCA at intervals of 1-2 months for up to four applications. A median of two treatments was required for patients who had no evidence of AIN at follow-up HRA examination. When analyzed on a per lesion basis, $73 \%$ of AIN- 1 patients and $71 \%$ of AIN$2 / 3$ patients had no evidence of AIN on follow-up HRA examination. The response was better for patients with two or fewer lesions. Patients were not prescribed analgesics and reported that treatment-related side effects were minimal. ${ }^{66}$ The authors concluded that TCA, because of its ease of use, low cost, and good safety profile, was a reasonable first-line therapy for patients with two or fewer AIN lesions. ${ }^{66}$

\section{Completing treatment of AIN}

AIN does not occur in isolation. Anogenital HPV infection causes other intraepithelial neoplasias that are named for the affected site, eg, penile and vulvar intraepithelial neoplasia. These lesions are the precursors of other anogenital malignancies, including invasive anal, penile, vulvar, and cervical carcinoma. All of these conditions have an increased prevalence in immunosuppressed patients. Therefore, treatment of AIN cannot be considered complete until the patient with AIN has been evaluated for these associated lesions.

\section{Preventing and treating AIN by vaccination}

Preventing HPV infection, would be expected to prevent HGAIN and anal cancer. There are two HPV vaccines available that prevent infection with HPV 16 and HPV 18, which are the HPV strains responsible for the majority of cervical and anal cancers. ${ }^{15-20}$ One of the vaccines, in addition to preventing HPV 16 and HPV 18 infection, also prevents HPV 6 and HPV 11 infection, which cause the majority of genital warts. Both HPV vaccines have been shown to be effective in preventing cervical intraepithelial neoplasia, the precursor lesion of cervical cancer. ${ }^{67,68}$ These vaccines are widely recommended for girls and women, but are not routinely recommended for administration to boys and men.

There are recent data showing that HPV vaccination can reduce persistent anal HPV infection and HGAIN among immunized MSM. In a randomized, placebo-controlled, double-blind primary prevention study, the quadrivalent HPV vaccine or placebo was given to 4065 healthy men and boys ${ }^{69} \mathrm{Of}$ these, $602 \mathrm{had}$ sex with male partners. Analysis of this cohort demonstrated that persistent anal infection with HPV 6, 11, 16, or 18 was reduced by $60 \%$ in the intention-totreat population and $95 \%$ in the per protocol cohort. HGAIN related to infection with HPV 6, 11, and 16 was reduced by $54 \%$ in the intention-to-treat population and $75 \%$ in the per protocol cohort. ${ }^{69}$ In a retrospective secondary prevention study from a single anorectal disease practice in New York City, rates of recurrent HGAIN in non-HIV-infected MSM who accepted or declined the quadrivalent HPV vaccine as part of routine medical care were compared..$^{70} \mathrm{MSM}$ who chose to receive the quadrivalent HPV vaccine were significantly less likely to have HGAIN or be infected with oncogenic HPV two years after vaccination..$^{70}$ There were no immunocompromised subjects enrolled in either of these studies, and the role of vaccination in preventing HGAIN in immunocompromised individuals is uncertain.

\section{Summary}

In the last two decades, the patient population with HGAIN has changed and the majority of those with HGAIN are now immunosuppressed. HRA mapping followed 
by ablation, either with infrared coagulation or cautery, overcomes some of the concerns associated with surgical excision of HGAIN. Ablation of AIN is a well tolerated destructive surgical procedure performed with local anesthesia on an outpatient basis, and is a useful treatment for a disease that should be expected to be recurrent. There are developing data suggesting that ablative treatment may change the natural history of HGAIN. Although there are many unanswered questions concerning ablative treatment in HIV-infected persons, the most important is whether successful ablative treatment of HGAIN reduces the incidence of anal squamous cell cancer and mortality in immunocompromised persons. The weakness of ablative treatment in HGAIN is that it treats the complications of HPV infection and does not directly treat the HPV infection itself. Determining the ideal method for destruction of HGAIN will require standardizing the treatment and then testing that treatment with carefully designed, multisite, randomized, clinical trials.

Available topical therapies have the advantage of being suitable for outpatient use and are well suited for treating widespread multifocal disease. Additionally, they offer the advantage of treating condyloma acuminatum, LGAIN, and HGAIN simultaneously. The principal disadvantage of the currently available topical therapies is they are difficult to apply and require adherence to a regime that is uncomfortable at best and at worst painful for months. Successful medical treatment of patients with HGAIN requires the treating clinician to work as an educator and a cheerleader to assist the patient in completing what is at best a long uncomfortable treatment. The goals of screening and treatment for HGAIN are reduction of morbidity, and treating patients when they have small, superficial, discrete premalignant lesions rather than when they progress to anal squamous cell carcinoma.

\section{Acknowledgments}

S Robert Harla and Jotam Pasipanodya are thanked for providing critical reviews of the manuscript. Dr Pasipanodya is also acknowledged for help with construction of the tables.

\section{Disclosure}

The author reports no conflicts of interest in this work.

\section{References}

1. Ho GY, Bierman R, Beardsley L, Chang CJ, Burk RD. Natural history of cervicovaginal papillomavirus infection in young women. $N$ Engl J Med. 1998;338:423-428.
2. Woodman CB, Collins S, Winter H, et al. Natural history of cervical human papillomavirus infection in young women: a longitudinal cohort study. Lancet. 2001;357:1831-1836.

3. Palefsky JM, Minkoff H, Kalish LA, et al. Cervicovaginal human papillomavirus infection in human immunodeficiency virus-1 (HIV)positive and high-risk HIV-negative women. J Natl Cancer Inst. 1999;91:226-236.

4. Critchlow CW, Surawicz CM, Holmes KK, et al. Prospective study of high grade anal squamous intraepithelial neoplasia in a cohort of homosexual men: influence of HIV infection, immunosuppression and human papillomavirus infection. AIDS. 1995;9:1255-1262.

5. Kiviat N, Rompalo A, Bowden R, et al. Anal human papillomavirus infection among human immunodeficiency virus-seropositive and -seronegative men. J Infect Dis. 1990;162:358-361.

6. Sun XW, Kuhn L, Ellerbrock TV, Chiasson MA, Bush TJ, Wright TC Jr. Human papillomavirus infection in women infected with the human immunodeficiency virus. $N$ Engl J Med. 1997;337:1343-1349.

7. Birkeland SA, Storm HH, Lamm LU, et al. Cancer risk after renal transplantation in the Nordic countries, 1964-1986. Int J Cancer. 1995;60:183-189.

8. Adami J, Gabel H, Lindelof B, et al. Cancer risk following organ transplantation: a nationwide cohort study in Sweden. Br J Cancer. 2003;89:1221-1227.

9. Del MA, Insacco E, Cinel A, Bonaldi L, Minucci D, Chieco-Bianchi L. Human papillomavirus infections of the genital region in human immunodeficiency virus seropositive women: integration of type 16 correlates with rapid progression. Eur J Gynaecol Oncol. 1994;15:50-58.

10. Mayaud P, Gill DK, Weiss HA, et al. The interrelation of HIV, cervical human papillomavirus, and neoplasia among antenatal clinic attenders in Tanzania. Sex Transm Infect. 2001;77:248-254.

11. Jamieson DJ, Duerr A, Burk R, et al. Characterization of genital human papillomavirus infection in women who have or who are at risk of having HIV infection. Am J Obstet Gynecol. 2002;186:21-27.

12. Levi JE, Kleter B, Quint WG, et al. High prevalence of human papillomavirus (HPV) infections and high frequency of multiple HPV genotypes in human immunodeficiency virus-infected women in Brazil. J Clin Microbiol. 2002;40:3341-3345.

13. Palefsky JM, Holly EA, Ralston ML, Jay N. Prevalence and risk factors for human papillomavirus infection of the anal canal in human immunodeficiency virus (HIV)-positive and HIV-negative homosexual men. J Infect Dis. 1998;177:361-367.

14. Ahdieh L, Klein RS, Burk R, et al. Prevalence, incidence, and type-specific persistence of human papillomavirus in human immunodeficiency virus (HIV)-positive and HIV-negative women. J Infect Dis. 2001;184:682-690.

15. Egelkrout EM, Galloway D. Biology of genital human papillomaviruses. In: Holmes K, Sparling P, Stamm W, editors. Sexually Transmitted Diseases, 4th ed. New York, NY: McGraw-Hill; 2008.

16. Khanna N, Brooks SE, Chen TT, Simsir A, Gordon NJ, Taylor G. Human papillomavirus absence predicts normal cervical histopathologic findings with abnormal Papanicolaou smears: a study of a universitybased inner city population. J Hum Virol. 2001;4:283-287.

17. Bosch FX, Lorincz A, Munoz N, Meijer CJ, Shah KV. The causal relation between human papillomavirus and cervical cancer. $J$ Clin Pathol. 2002;55:244-265.

18. Walboomers JM, Jacobs MV, Manos MM, et al. Human papillomavirus is a necessary cause of invasive cervical cancer worldwide. J Pathol. 1999;189:12-19.

19. Hoots BE, Palefsky JM, Pimenta JM, Smith JS. Human papillomavirus type distribution in anal cancer and anal intraepithelial lesions. Int $J$ Cancer. 2009; 124:2375-2383.

20. Abramowitz L, Jacquard AC, Jaroud F, et al. Human papillomavirus genotype distribution in anal cancer in France: the EDiTH V study. Int J Cancer. 2011;129:433-439.

21. Frisch M, Glimelius B, van den Brule AJ, et al. Sexually transmitted infection as a cause of anal cancer. N Engl J Med. 1997;337: $1350-1358$. 
22. Zbar AP, Fenger C, Efron J, Beer-Gabel M, Wexner SD. The pathology and molecular biology of anal intraepithelial neoplasia: comparisons with cervical and vulvar intraepithelial carcinoma. Int J Colorectal Dis. 2002; 17:203-215.

23. Watson AJ, Smith BB, Whitehead MR, Sykes PH, Frizelle FA. Malignant progression of anal intra-epithelial neoplasia. ANZ J Surg. 2006;76:715-717.

24. D'Souza G, Wiley DJ, Li X. Incidence and epidemiology of anal cancer in the Multicenter AIDS Cohort Study. J Acquir Immune Defic Syndr. 2008:48:491-499.

25. Devaraj B, Cosman BC. Expectant management of anal squamous dysplasia in patients with HIV. Dis Colon Rectum. 2006;49:36-40.

26. Scholefield JH, Castle MT, Watson NF. Malignant transformation of high-grade anal intraepithelial neoplasia. Br J Surg. 2005;92: $1133-1136$

27. Machalek DA, Poynten M, Jin F, et al. Anal human papillomavirus infection and associated neoplastic lesions in men who have sex with men: a systematic review and meta-analysis. Lancet Oncol. 2012;13:487-500.

28. Weis SE, Vecino I, Pogoda JM, et al. Prevalence of anal intraepithelial neoplasia defined by anal cytology screening and high-resolution anoscopy in a primary care population of HIV-infected men and women. Dis Colon Rectum. 2011;54:433-441.

29. Goldman S, Auer G, Erhardt K, Seligson U. Prognostic significance of clinical stage, histologic grade, and nuclear DNA content in squamouscell carcinoma of the anus. Dis Colon Rectum. 1987;30:444-448.

30. Johnson LG, Madeleine MM, Newcomer LM, Schwartz SM, Daling JR Anal cancer incidence and survival: the surveillance, epidemiology, and end results experience, 1973-2000. Cancer. 2004;101:281-288.

31. Ajani JA, Winter KA, Gunderson LL, et al. Fluorouracil, mitomycin, and radiotherapy vs fluorouracil, cisplatin, and radiotherapy for carcinoma of the anal canal: a randomized controlled trial. JAMA. 2008;299:1914-1921.

32. Macaya A, Munoz-Santos C, Balaguer A, Barbera MJ. Interventions for anal canal intraepithelial neoplasia. Cochrane Database Syst Rev. 2012;12:CD009244.

33. Brown SR, Skinner P, Tidy J, Smith JH, Sharp F, Hosie KB. Outcome after surgical resection for high-grade anal intraepithelial neoplasia (Bowen's disease). Br J Surg. 1999;86:1063-1066.

34. Chin-Hong PV, Palefsky JM. Human papillomavirus anogenital disease in HIV-infected individuals. Dermatol Ther. 2005;18:67-76.

35. Goldstone S. A stand against expectant management of anal dysplasia. Dis Colon Rectum. 2006;49:1648-1649.

36. Cleary RK, Schaldenbrand JD, Fowler JJ, Schuler JM, Lampman RM. Treatment options for perianal Bowen's disease: survery of American Society of Colon and Rectal Surgeons Members. Am Surg. 2000;66: 686-688.

37. Scholefield JH, Ogunbiyi OA, Smith JH, Rogers K, Sharp F. Treatment of anal intraepithelial neoplasia. Br J Surg. 1994;81:1238-1240.

38. Marchesa P, FazioVW, Oliart S, Goldblum JR, Lavery IC. Perianal Bowen's disease: a clinicopathologic study of 47 patients. Dis Colon Rectum. 1997;40:1286-1293.

39. Jay N, Berry JM, Hogeboom CJ, Holly EA, Darragh TM, Palefsky JM. Colposcopic appearance of anal squamous intraepithelial lesions: relationship to histopathology. Dis Colon Rectum. 1997;40:919-928.

40. Wilson W, Taubert KA, Gewitz M, et al. Prevention of infective endocarditis: guidelines from the American Heart Association: a guideline from the American Heart Association Rheumatic Fever, Endocarditis, and Kawasaki Disease Committee, Council on Cardiovascular Disease in the Young, and the Council on Clinical Cardiology, Council on Cardiovascular Surgery and Anesthesia, and the Quality of Care and Outcomes Research Interdisciplinary Working Group. Circulation. 2007;116:1736-1754.

41. American Academy of Orthopaedic Surgeons. Antibiotic prophylaxis for bacteremia in patients with joint replacements. Available from: http://www. aaos.org/about/papers/advistmt/1033asp. Accessed August 29, 2012.

42. Goldstone SE, Kawalek AZ, Huyett JW. Infrared coagulator: a useful tool for treating anal squamous intraepithelial lesions. Dis Colon Rectum. $2005 ; 48: 1042-1054$
43. Pineda CE, Berry JM, Jay N, Palefsky JM, Welton ML. High-resolution anoscopy targeted surgical destruction of anal high-grade squamous intraepithelial lesions: a ten-year experience. Dis Colon Rectum. 2008;51:829-835.

44. Stier EA, Goldstone SE, Berry JM, et al. Infrared coagulator treatment of high-grade anal dysplasia in HIV-infected individuals: an AIDS malignancy consortium pilot study. J Acquir Immune Defic Syndr. 2008;47:56-61.

45. Cranston RD, Hirschowitz SL, Cortina G, Moe AA. A retrospective clinical study of the treatment of high-grade anal dysplasia by infrared coagulation in a population of HIV-positive men who have sex with men. Int J STD AIDS. 2008;19:118-120.

46. Goldstone RN, Goldstone AB, Russ J, Goldstone SE. Long-term follow-up of infrared coagulator ablation of anal high-grade dysplasia in men who have sex with men. Dis Colon Rectum. 2011;54: 1284-1292.

47. Weis SE, Vecino I, Pogoda JM, Susa JS. Treatment of high-grade anal intraepithelial neoplasia with infrared coagulation in a primary care population of HIV-infected men and women. Dis Colon Rectum. 2012;55:1236-1243.

48. Chang GJ, Berry JM, Jay N, Palefsky JM, Welton ML. Surgical treatment of high-grade anal squamous intraepithelial lesions: a prospective study. Dis Colon Rectum. 2002;45:453-458.

49. Marks DK, Goldstone SE. Electrocautery ablation of high-grade anal squamous intraepithelial lesions in HIV-negative and HIV-positive men who have sex with men. J Acquir Immune Defic Syndr. 2012;59:259-265.

50. Watemberg S, Landau O, Avrahami R, Kaplan I, Giler S, Kott I. Successful treatment of anal tumors with $\mathrm{CO}_{2}$ laser in elderly, high-risk patients. J Clin Laser Med Surg. 1996;14:115-117.

51. Nathan M, Hickey N, Mayuranathan L, Vowler SL, Singh N. Treatment of anal human papillomavirus-associated disease: a long term outcome study. Int J STD AIDS. 2008;19:445-449.

52. Sillman FH, Sedlis A, Boyce JG. A review of lower genital intraepithelial neoplasia and the use of topical 5-fluorouracil. Obstet Gynecol Surv. $1985 ; 40: 190-220$

53. Love WE, Bernhard JD, Bordeaux JS. Topical imiquimod or fluorouracil therapy for basal and squamous cell carcinoma: a systematic review. Arch Dermatol. 2009;145:1431-1438.

54. Maiman M, Watts DH, Andersen J, Clax P, Merino M, Kendall MA. Vaginal 5-fluorouracil for high-grade cervical dysplasia in human immunodeficiency virus infection: a randomized trial. Obstet Gynecol. 1999;94:954-961

55. Danso D, Lyons F, Bradbeer C. Cervical screening and management of cervical intraepithelial neoplasia in HIV-positive women. Int J STD AIDS. 2006;17:579-584.

56. Duong TH, Flowers LC. Vulvo-vaginal cancers: risks, evaluation, prevention and early detection. Obstet Gynecol Clin North Am. 2007;34:783-802.

57. Graham BD, Jetmore AB, Foote JE, Arnold LK. Topical 5-fluorouracil in the management of extensive anal Bowen's disease: a preferred approach. Dis Colon Rectum. 2005;48:444-450.

58. Snyder SM, Siekas L, Aboulafia DM. Initial experience with topical fluorouracil for treatment of HIV-associated anal intraepithelial neoplasia. J Int Assoc Physicians AIDS Care (Chic). 2011;10:83-88.

59. Richel O, Wieland U, de Vries HJ, et al. Topical 5-fluorouracil treatment of anal intraepithelial neoplasia in human immunodeficiency virus-positive men. Br J Dermatol. 2010;163:1301-1307.

60. Ganjian S, Ourian AJ, Shamtoub G, Wu JJ, Murase JE. Off-label indications for imiquimod. Dermatol Online J. 2009;15:4.

61. Gutzmer R, Kaspari M, Vogelbruch M, et al. Successful treatment of anogenital Bowen's disease with the immunomodulator imiquimod, and monitoring of therapy by DNA image cytometry. $\mathrm{Br} J$ Dermatol. 2002;147:160-165.

62. Kreuter A, Hochdorfer B, Stucker M, et al. Treatment of anal intraepithelial neoplasia in patients with acquired HIV with imiquimod 5\% cream. J Am Acad Dermatol. 2004;50:980-981. 
63. Wieland U, Brockmeyer NH, Weissenborn SJ, et al. Imiquimod treatment of anal intraepithelial neoplasia in HIV-positive men. Arch Dermatol. 2006;142:1438-1444.

64. Fox PA, Nathan M, Francis N, et al. A double-blind, randomized controlled trial of the use of imiquimod cream for the treatment of anal canal high-grade anal intraepithelial neoplasia in HIV-positive MSM on HAART, with long-term follow-up data including the use of open-label imiquimod. AIDS. 2010;24:2331-2335.

65. Workowski KA, Berman S. Sexually transmitted diseases treatment guidelines, 2010. MMWR Recomm Rep. 2010;59:1-110.

66. Singh JC, Kuohung V, Palefsky JM. Efficacy of trichloroacetic acid in the treatment of anal intraepithelial neoplasia in HIV-positive and HIVnegative men who have sex with men. J Acquir Immune Defic Syndr. 2009;52:474-479.
67. Garland SM, Hernandez-Avila M, Wheeler CM, et al. Quadrivalent vaccine against human papillomavirus to prevent anogenital diseases. N Engl J Med. 2007;356:1928-1943.

68. The FUTURE II Group. Quadrivalent vaccine against human papillomavirus to prevent high-grade cervical lesions. $N$ Engl J Med. 2007;356:1915-1927.

69. Palefsky JM, Giuliano AR, Goldstone S, et al. HPV vaccine against anal HPV infection and anal intraepithelial neoplasia. $N$ Engl J Med. 2011;365:1576-1585.

70. Swedish KA, Factor SH, Goldstone SE. Prevention of recurrent high-grade anal neoplasia with quadrivalent human papillomavirus vaccination of men who have sex with men: a nonconcurrent cohort study. Clin Infect Dis. 2012;54:891-898.

\section{Publish your work in this journal}

OncoTargets and Therapy is an international, peer-reviewed, open access journal focusing on the pathological basis of all cancers, potential targets for therapy and treatment protocols employed to improve the management of cancer patients. The journal also focuses on the impact of management programs and new therapeutic agents and protocols on

\section{Dovepress}

patient perspectives such as quality of life, adherence and satisfaction The manuscript management system is completely online and includes a very quick and fair peer-review system, which is all easy to use. Visit http://www.dovepress.com/testimonials.php to read real quotes from published authors.

Submit your manuscript here: http://www.dovepress.com/oncotargets-and-therapy-journal 